\title{
The effect of melatonin on the liver of rats exposed to microwave radiation
}

\author{
Djordjevic $\mathrm{B}^{1}$, Sokolovic $\mathrm{D}^{1}$, Kocic $\mathrm{G}^{1}$, Veljkovic $\mathrm{A}^{1}$, Despotovic $\mathrm{M}^{1}$, Basic $\mathrm{J}^{1}$, \\ Jevtovic-Stoimenov $\mathrm{T}^{1}$,Sokolovic $\mathrm{DM}^{2}$
}

Department of Biochemistry, Faculty of Medicine, University of Nis, Serbia. brankadjordjevic83@gmail.com

\begin{abstract}
Objectives: We aimed to clarify if melatonin treatment (2 mg/kg i.p.) may favorably impact the liver tissue in rats exposed to microwave radiation. The experiment was performed on 84 six-weeks-old Wistar male rats exposed for $4 \mathrm{~h}$ a day, for 20, 40 and 60 days, respectively, to microwaves ( $900 \mathrm{MHz}, 100-300$ microT, 54$160 \mathrm{~V} / \mathrm{m}$ ). Rats were divided in to four groups: I (control) - rats treated with saline, II (Mel) - rats treated with melatonin, III (MWs) - microwave exposed rats, IV (MWs + Mel) - MWs exposed rats treated with melatonin. We evaluated oxidative stress parameters (malondialdehyde and carbonyl group content), catalase, xanthine oxidase, deoxyribonuclease I and II activity.

Background: Oxidative stress is the key mechanism of the microwave induced tissue injury. Melatonin, a lipophilic indoleamine primarily synthesized and released from the pineal gland is a powerful antioxidant.

Results: Exposure to microwaves caused an increase in malondialdehyde after $40(p<0.01)$, protein carbonyl content after $20(p<0.05)$, catalase $(p<0.05)$ and xantine oxidase activity $(p<0.05)$ after 40 days. Increase in deoxyribonuclease I activity was observed after 60 days $(p<0.05)$, while deoxyribonuclease II activity was unaffected. Melatonin treatment led to malondialdehyde decrease after 40 days $(p<0.05)$, but surprisingly had no effect on other analyzed parameters.

Conclusion: Melatonin exerts certain antioxidant effects in the liver of rats exposed to microwaves, by diminishing the intensity of lipid peroxidation(Fig. 6, Ref. 32). Text in PDF www.elis.sk.

Key words: melatonin, microwaves, liver, oxidative stress, DNAse.
\end{abstract}

\section{Introduction}

Microwaves (MWs) are electromagnetic waves with wavelengths ranging from one meter to one millimeter or equivalently, with frequencies between $0.3 \mathrm{GHz}$ and $300 \mathrm{GHz}$. During the last few decades, there has been an increase in the number of devices that emit microwaves. Such devices are used predominantly in telecommunications, but also in other society sectors and in households. Nowadays, we are facing growing public concerns regarding the potential hazard to man from exposure to microwaves. By far the greatest public concern has been that exposure to microwaves may cause cancer. Of the epidemiological studies addressing possible links between MW exposure and excess risk of cancer, some positive findings were reported for leukemia and brain tumors, yet up to date results remain inconclusive (1).

However, most of the studies on animals regarding the in vivo effect of MW exposure have reported evidence of changes in cellular biochemistry such as increased reactive oxygen species gen-

${ }^{1}$ Department of Biochemistry, Faculty of Medicine, University of Nis, Serbia, and ${ }^{2}$ Institutefor Blood Transfusion in Nis, Clinical center Nis, Serbia

Address for correspondence: B.Djordjevic, Department of Biochemistry, Faculty of Medicine, University of Nis. Bul. dr Zorana Djindjica 81,18000 Nis, Serbia.

Acknowledgements: This work was supported by the Ministry of Education and Science, Republic of Serbia (Project 43012). eration. Reactive oxygen species (ROS) are generated as by-products of cellular metabolism, primarily in the mitochondria. When cellular production of ROS overwhelms its antioxidant capacity, damage to cellular macromolecules such as lipids, proteins, and DNA may ensue (2). Lipid peroxidation is a free radical-induced oxidation of polyunsaturated fatty acids within biological membranes. MDA is a break down product of lipid peroxidation and thus serves as a reliable marker of oxidative stress. Protein carbonylgroupsare also approved biomarker of oxidative stress (3).

Normally, the reactive oxygen species (ROS) are neutralized by highly efficient antioxidant systems in the body. These systems include antioxidant enzymes such as catalase (4). Catalase (EC 1.11.1.6) catalyzes the decomposition of hydrogen peroxide to water and oxygen, therefore preventing generation of highly toxic hydroxyl radicals trough Fenton's reaction (5).

Xanthine oxidase (XO, EC 1.17.3.2) is an enzyme that generates reactive oxygen species (6). It plays an important role in the catabolism of purines and catalyzes the oxidation of hypoxanthine to xanthine and xanthine to uric acid. The same protein can also have xanthine dehydrogenase activity (XDH, EC 1.17.1.4). Most of the protein in the liver exists in the form with xanthine dehydrogenase activity, but it can be converted to xanthine oxidase by reversible sulfhydryl oxidation or by irreversible proteolytic modification (7).

DNaseI (EC 3.1.21.1) and II (EC 3.1.22.1) are endonucleases involved inDNA degradation process during apoptosis. DNA of 
apoptotic cells is destroyed by DNAse II (acid DNAse) in lysosomes of the cells that have phagocytized the corpses. DNAse I (alkaline DNAse) destroys DNA that is released into the extracellular compartment (8) and mediates internucleosomal DNA degradation in human cells undergoing drug-induced apoptosis (9).

Melatonin (N-acetyl-5-methoxytryptamine) is a neurohormone, primarily synthesized and released from pineal gland. Besides its function as synchronizer of the biological clock, melatonin also exerts a powerful antioxidant activity. Melatonin is able to neutralize a number of free radicals such as superoxide anion, hydrogen peroxide, hydroxyl radical, singlet oxygen, peroxinitrite anion, nitric oxide and hydrochloric acid directly (10).

The present study was designed to evaluate the effects of microwaves on oxidative stress parameters (such as MDA, protein carbonyls formation, CAT and XO activity)and DNA fragmentation (Dnase I and II activity) in the liver tissue of rats exposed to microwaves, as well as the possible protective effects of melatonin onthose parameters in exposure periods of 20, 40, and 60 days.

\section{Methods}

\section{Chemicals}

All reagents were of the highest commercial grade available. Chemicals used for the purpose of this experiment were of analytical grade. Melatonin(pro analysi purity) was obtained from ICN Galenikaa.d. (Belgrade, Serbia). All drug solutions were prepared on the day of experiment.

\section{Animal model}

Experiments were performed on 84 albino adult maleWistar rats (6-8 weeks old, $150 \mathrm{~g}$ ), bred in the vivarium of the Biomedical Research Institute, at Faculty of Medicine, University of Nis, under conventional laboratory conditions. Animals were purchased from the farm at Serbian Military Academy in Belgrade.Animals were collectively housed in plastic cages $(30 \mathrm{x} 40 \mathrm{x} 40 \mathrm{~cm})$ and had ad libitum access to standard laboratory food and water. The housing room was maintained at $24^{\circ} \mathrm{C}$ with $42 \pm 5 \%$ relative humidity and had $12 \mathrm{~h}$ light-dark cycle (exposure to light from 06:00 AM to $06: 00 \mathrm{PM}$ ).

Animals used for the procedure were treated in strict accordance with the NIH Guide for Care and Use of Laboratory Animals (1996). All experiments on animals had been approved by the Animal Ethics Board of the Faculty of Medicine, Universityof Nis and were performed according to these guidelines.

\section{Microwave exposure}

Animals were exposed to MWs for 20, 40 and 60 days (4 h/ day during light period) respectively. The exposure system consisted of a plastic cage containing a mobile phone (NOKIA 3110 , Nokia Mobile Phones Ltd.) with antenna positioned downwards. An electromagnetic near field continuous wave signal in $900 \mathrm{MHz}$ frequency range (GSM frequency band-mobile transmit) was emitted by the exposure system.Mobile test phone was connected to PC with appropriate software moduleusing PCDKcommunication test set.During MW exposure animals were able to move freely in a pure (i.e. lacking any metallic fittings) plastic cage.

Electromagnetic field parameters in the cage $(4.68-8.69 \mu \mathrm{T}$, 9.88-18.356 V/m) were measured several times during experimental exposure by means of EMF meter (AARONIASPECTRAN HF6080). The whole-body average specific energy absorption rate (SAR) rate was estimated to $0.089 \mathrm{~W} / \mathrm{kg}$ using rotating ellipsoid rat model.

\section{Experimental design}

Animals were randomly divided into 4 experimental groups with 21 animals in each group: I group (control)- rats treated with $0.9 \%$ saline, II group (Mel) - rats treated with melatonin, III group (MWs)-MW exposed rats, IV group (MWs + Mel)-MW exposed rats treated with melatonin.Melatonin was administered intraperitoneally (i.p.) in a single daily dose of $2 \mathrm{mg} . \mathrm{kg}^{-1}$ body weight.

Animals in all experimental groups (groups III and IV) were exposed to microwave radiation for 4 hours/ day and then moved to rooms without any sources of electromagnetic field.

Melatonin was administered intraperitoneally every morning at $08.00 \mathrm{AM}$, at a single dose of $2 \mathrm{mg} / \mathrm{kg}$ body weightas proposed by Drago et al(11). In control rats, isotonic saline solution (equal to the volume of melatonin) was given intraperitoneallyeveryday during the follow up.

Seven animals from each group were sacrificed after 20, 40 and 60 days of experiment. Rats were anesthetized by ketamine $\mathrm{HCl}(50 \mathrm{mg} / \mathrm{kg}$ ), which was administered intraperitoneally (i.p.). Before sacrificing, each rat liver was surgically removed from the abdomen.

\section{Tissue sampling}

Extirpated liver tissue was prepared as $10 \%$ homogenate. In order to assess oxidative stress parameters and DNA fragmentation, liver tissue was cut into small pieces and homogenized in ice-cold water, by means of homogenizer (IKA Works de BrasilLtdaTaquara, RJ 22713-00). Homogenates $(10 \% \mathrm{w} / \mathrm{v})$ were centrifuged at $1500 \mathrm{x}$ g for $10 \mathrm{~min}$. at $4{ }^{\circ} \mathrm{C}$.

\section{Biochemical analysis}

Determination of MDA.Malondialdehyde in the liver tissue was spectrophotometrically determined, based on the chemical reaction between thiobarbituric (TBA) acid and MDA as described by Ohkawa et al (12). Absorbance was read at $532 \mathrm{~nm}$. Malondialdehyde (MDA - lipid peroxidation end product) concentration was calculated using the MDA molecular absorbance coefficient $\left(1.56 \times 10^{-5} \mathrm{~mol}_{\mathrm{cm}} \mathrm{cm}^{-1}\right)$ and expressed as nanomoles $\backslash \mathrm{mg}\left(\mathrm{nM}^{\mathrm{m}} \mathrm{mg}^{-1}\right)$ of protein.

Determination of protein oxidation. Protein carbonyls content, used as a quantification of oxidative modified proteins, was determined spectrophotometrically (13)using 2.4 dinitrophenylhydrazine. Reactive carbonyl derivates were determined using DPNH molar extinction coefficient at $370 \mathrm{~nm}\left(22 \times 10^{3} \mathrm{~L} / \mathrm{mol} / \mathrm{cm}\right)$ and expressed as $\mu \mathrm{mol} / \mathrm{g}$ of protein.

Determination of CAT activity. Catalase activity was measuredspectrophotometrically at $405 \mathrm{~nm}$ as described by Góth (14). 
96-100

According to this method serum or homogenate was incubated in $\mathrm{H}_{2} \mathrm{O}_{2}$ substrateand the enzymatic reaction was stopped by adding ammonium molybdate. Activity was expressed in micromoles $\backslash$ $\mathrm{mg}\left(\mu \mathrm{M} \cdot \mathrm{mg}^{-1}\right)$ protein.

Determination of XO activity. Xanthine oxidaseactivity in liver homogenate was estimated by the amount of uric acid produced for fixed time interval. In brief, reaction mixture containing 0.1 $\mathrm{ml}$ liver homogenate and $0.1 \mathrm{M}$ Tris/ $\mathrm{HCl}$ buffer, $\mathrm{pH} 7.4$, in a final volume of $2.5 \mathrm{ml}$ was pre-incubated for $15 \mathrm{~min}$ at $37^{\circ} \mathrm{C}$. The reaction was started by adding $0.5 \mathrm{ml}$ of $0.6 \mathrm{mMxanthine}$. The oxygendependent $\mathrm{XO}$ activity was estimated by the increase of the uric acid content as a result of incubation of this reaction mixture for 30 $\min$ at $37^{\circ} \mathrm{C}$. The uric acid content was calculated by the increase in absorbency at $293 \mathrm{~nm}$ against blank, which was run parallel with the reaction mixture without xanthine. Molar extinction coefficient of $7.6 \times 10^{-3} \mathrm{M} . \mathrm{cm}^{-1}$ was used for this purpose (15). XO activity was also expressed as $\mathrm{U} / \mathrm{mg}$ tissue protein in liver homogenate.

Determination of alkaline-DNase I and acid-DNase II activity. Alkaline and acid DNase activity were determined as described byBartholeyns et al (16). According to this method, DNA was used as substrate. Alkaline DNase I activity was determined at optimum $\mathrm{pH}=7.4$ using Tris- $\mathrm{HCl}$ buffer, with the addition of $\mathrm{Mg}^{2+}$ ions as activator and the acid DNase II activity, using acetate bufferat optimum $\mathrm{pH}=5.0$.

Determination of proteins.Protein content in liver was determined according to Lowry's method (17), using bovine serum albumin as standard.

\section{Statistical analysis}

Results were presented as means \pm SD. Data were analyzed using one way ANOVA, performed by means of commercially available statistical software package (SPSS ${ }^{\circledR}$ for Windows). Statistical significance was set to $\mathrm{p}<0.05$.

\section{Results}

The mean MDA values are shown in Figure 1. The results showed that the MDAlevels in MWs (III) group were significantly higher when compared to the controlafter 40 and 60 dayslong exposure to microwaves $(\mathrm{p}<0.01)$. However, MDA levels after 20 days of exposure were slightly, but still not significantly elevated. Decreased MDA levels in MWs+Mel (IV) group were observed after 40 days and 60 days, when compared to MWs group $(\mathrm{p}<0.05)$.

Protein carbonyls content was significantly higher in MWs group when compared to control after 20, 40 and 60 days ( $p<0.05 ; p$ $<0.05 ; \mathrm{p}<0.001$ ) of exposure to MWs. However, there were no significant differences in the protein carbonyls content mean values between MW and MWs+Melgroups i.e.melatoninadministration had no significant effect on protein carbonyls contentin liver tissue of MW radiation exposed animals (Fig. 2).

Catalase activity was found to behigher in MWs group in comparison to control and Mel group after 40 days and 60 days ( $<<$ 0.05 ) of MW exposure (Fig. 3).As shown in Figure 4, XO activity was significantly higher in MW group after 40 and 60 days $(\mathrm{p}<$ 0.05 ) when compared to control and Mel group.Melatonin admi-

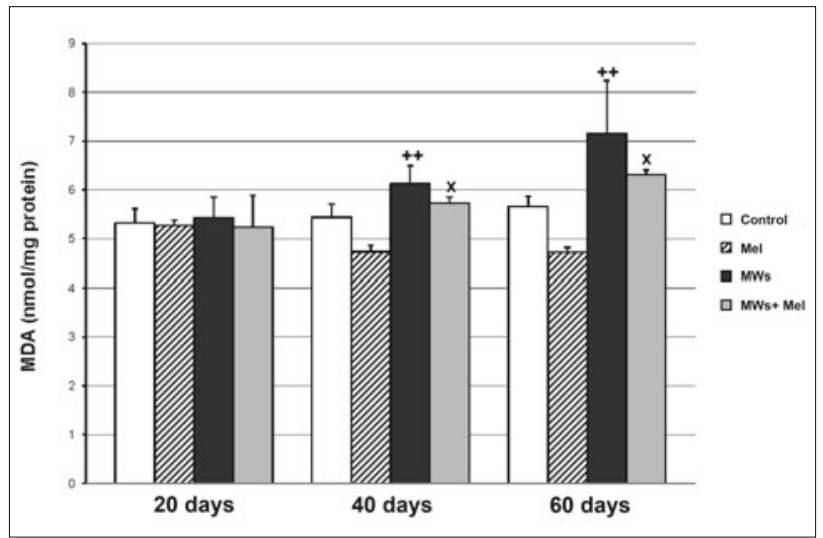

Fig. 1.The effect of melatonin (Mel) on lipid peroxidation (MDA level $-\mu \mathrm{mol} / \mathrm{mg}$ protein) in the liver of rats exposed to microwave radiation. ${ }^{++} p<0.001$ (vs control); ${ }^{x} \mathbf{p}<0.05$ (vs MWs).

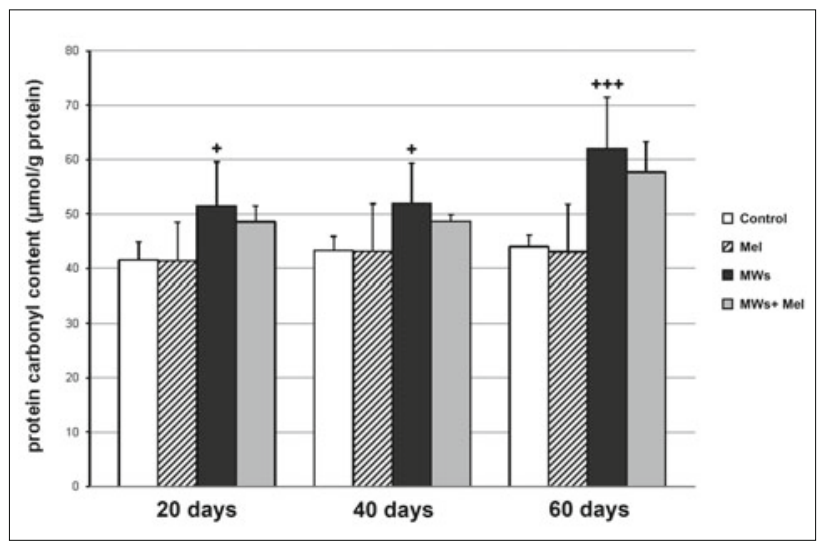

Fig. 2.Concentration of carbonyl groups ( $\mu \mathrm{mol} / \mathrm{g}$ protein) in the liver of rats exposed to microwave radiation (MW). $+\mathbf{p}<0.05$ (vs control and Mel); $+++p<0.001$ (vs control and Mel).

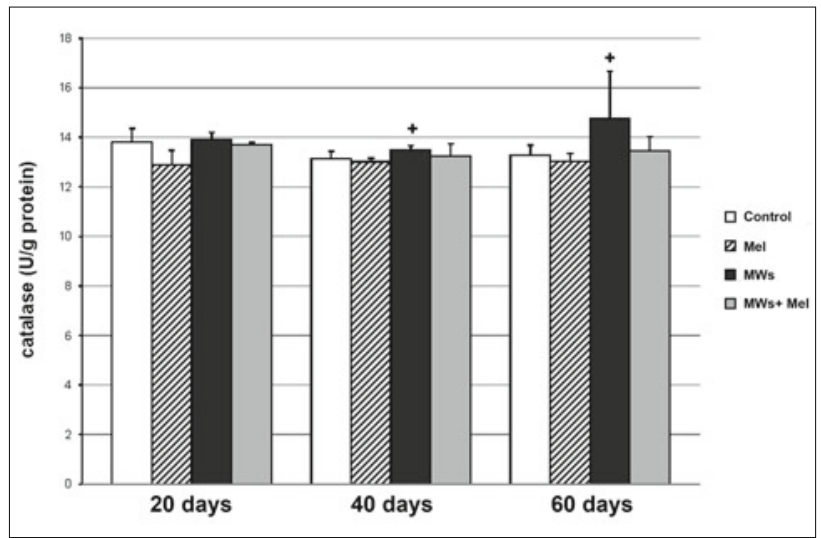

Fig. 3.Catalase (CAT - U/g protein) inthe liver tissue of rats exposed to microwave radiation.

$++\mathbf{p}<0.05$ (vs control and Mel).

nistration to irradiated animals (MWs+Melgroup) was not able to prevent observed changes in CAT and XO activity.

Alkaline-DNaseI activity was increased in MWs group after 60 days $(\mathrm{p}<0.05$ ) of exposure when compared to control and Mel group (Fig. 5). Acid-DNase II activity in the liver tissue, however, 


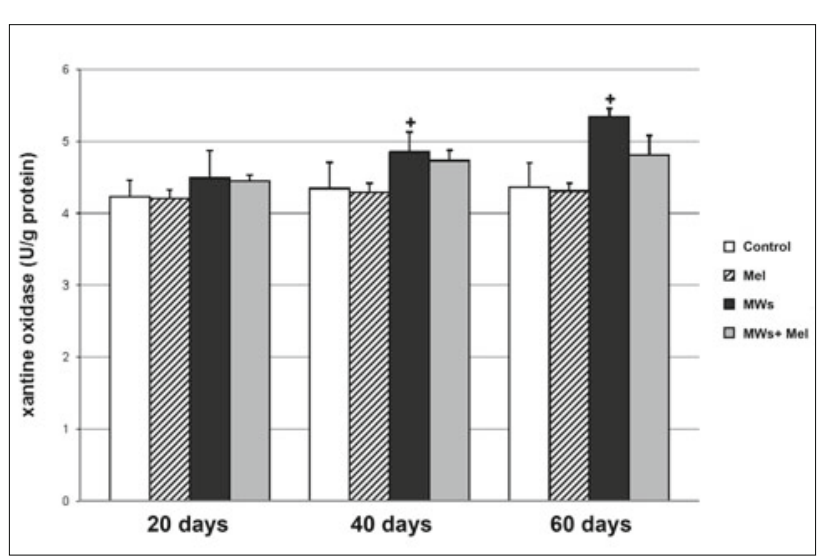

Fig. 4.Xanthine oxidase (XO) activity (U/g protein) in the liver tissue of rats exposed to microwave radiation. $++p<0.05$ (vs control and Mel).

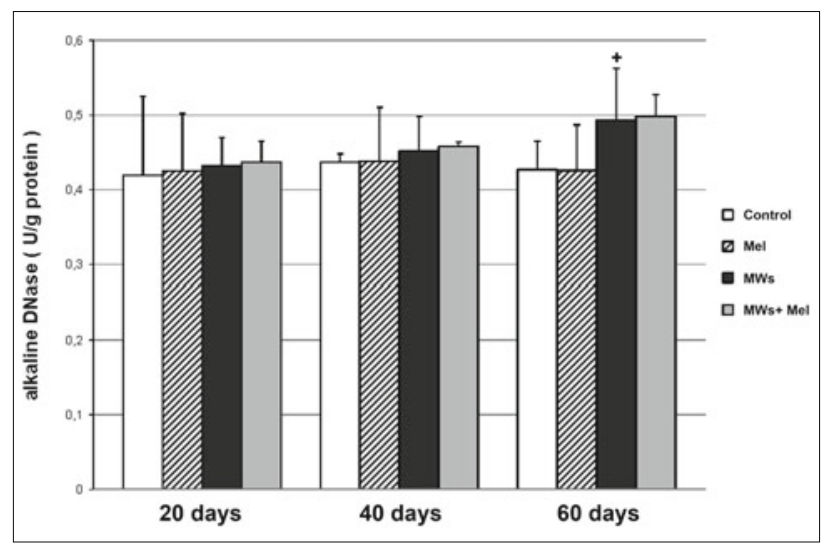

Fig. 5.Alkaline Dnase (DNAse I) activity(U/g protein) in the liver tissue of rats exposed to microwave radiation. $++p<0.05$ (vs control and Mel).

was found not to be affected by exposure to MWs(Fig. 6).Melatonin administration had no significant effect on alkaline-Dnase I andacid-Dnase Ilactivity in the liver tissue of MW exposed rats.

\section{Disscusion}

Oxidative stress represents an imbalance between reactive oxygen species generation and a biological system's ability to detoxify those molecules and to repair the resulting damage. It has been proved that oxidative stress develops in response to microwave radiation exposure (18-21). Studies have also demonstrated that antioxidants such ascaffeic acid phenyl ester, n-acetyl cysteineandepigallocatechin-gallateprevent oxidative stress caused by microwave exposure inanimal liver $(22,23)$.

Malondialdehyde level was found to be increased in various organs of animals exposed to MWs $(19-21,24,25)$ including liver $(22,26,27)$. Our results show as well, that MDA levelsare increased in liver tissue of rats exposed to microwaves after prolonged exposition period (40 and 60 days). The observed increase in MDA level was, according to our results, dependent on the exposure duration. However, we failed to demonstrate the significant change in MDA level in animals exposed to MWs for 20 days, previously reported by (27), probably due to the differences in average SAR $(0,09 \mathrm{~W} /$

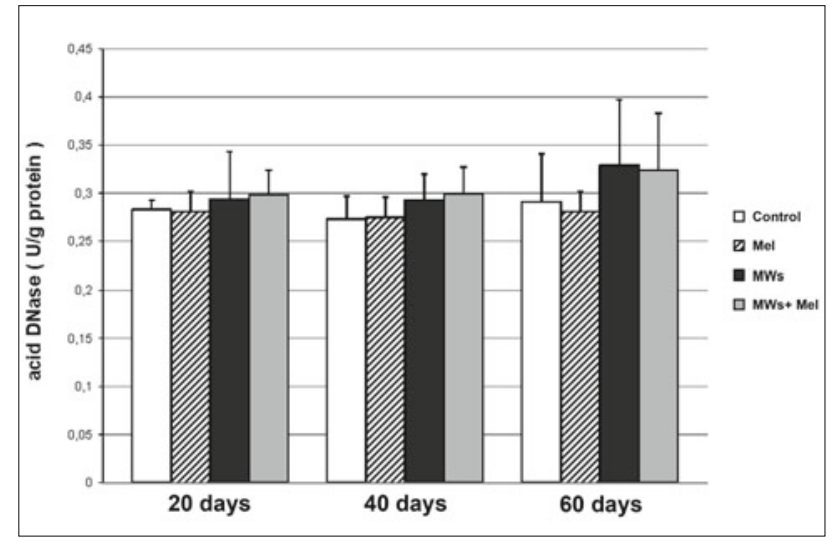

Fig. 6.AcidDnase (DNAse II) (U/g protein) activity in the liver tissue of rats exposed to microwave radiation. NS.

$\mathrm{kg}$ vs $1,2 \mathrm{~W} / \mathrm{kg}$ ) and experimental set up. Melatonin administration to irradiated animals ameliorated the radiation effect on lipid peroxidation in the liver tissuein a significant level.Changes in MDA level in group both irradiated and treated with melatonin occurred simultaneously with the increase in MDA level in irradiated group. Those data suggest that protective effect of melatonin is probably mediated by its direct free radical scavenging activity.

Protein carbonyls are formed through ROS mediated oxidation of amino acid residues in protein molecules (28). Increased protein carbonyl groups are reported previously in the brain of animals chronically exposed to microwaves (24). According to our results, protein carbonyls are significantly elevated in the liver of rats exposed to microwaves after 20,40 and 60 days of exposure, therefore suggesting that proteins are probably the first target for ROS molecules oxidative action. The proteolytic conversion of xanthine dehydrogenase to xanthine oxidase provides another enzymatic source of reactive oxygen species in vivo (7). Xanthine oxidase activity is already reported to be elevated in liver of animals exposed to MW radiation (22). Our results showed that the increase in xanthine oxidase activity occurred simultaneously (after 40 and 60 days) with an increase in lipid peroxidation levels, therefore suggesting the role of this enzyme in ROS generation and oxidative stress. The fact that described processes are following the initial increase in protein oxidation suggests the importance of xanthine oxidase transformation in initial phase of microwave exposure induced damage.

Catalase activity is found to be higher in organs of animals exposed to MWs $(22,25)$. We also found higher catalase activity in irradiated animals. Catalase activity may be elevated as compensatory mechanism in animals exposed to MWs, due to microwave induced oxidative stress.

Melatonin protective action on microwave induced oxidative stress has already been proven in the brain (24). Furthermore, melatonin was proved to prevent histological changes in the skin of rats exposed tomicrowaves (29). Surprisingly, melatonin administration had little effect on protein carbonyls content, catalase and xanthine oxidase activity in the liver tissue of microwave exposed rats.

Apoptosis starts withblebbing of the cell membrane, followed by degradation of chromosomal DNA by nucleases, resulting in 
condensation and fragmentation of DNA itselfand finally in phagocytosis of cell fragments (30). It has already been reported that DNase I mediates internucleosomal DNA degradation in human cells undergoing drug-induced apoptosis (9). Yet, DNase I has been primarilycharacterizedas secreted protein involved in the DNA waste management outside the cell (8). DNase II activity was as well detected in apoptotic cells (31). Since intracellular acidification occurs in many apoptotic cells, it was suggested that DNase II released from lysosomes, could be involved in nuclear DNA digesting (31). Both DNase I and II are involved in DNA fragmentation in oxidative stress induced apoptosis and necrosis (32).In the present study, DNase I activity was found to be elevated in the liver tissue of animals after 60 days long exposure to microwaves. However, DNAse II activity was not affected by microwave exposure. Melatonin administration had little effect on DNAse I and II activity. To the best of our knowledge, results regarding the endonuclease activity and protein carbonyl content in the liver tissue of microwave exposed animals have not been reported previously.

Based on the results of the present study it can be concluded that microwave exposure caused increase in the level of lipid peroxides and protein carbonyls which can, in part, be ascribed to the increase in xanthine oxidase activity. Compensatory rise in the catalase activity as a consequence of increased ROS formation was noted as well. Melatonin exerted certain protective effect by diminishing the level of lipid peroxides, but had little effect on protein carbonyls, catalase,xanthine oxidase and endonucleases activity.

\section{References}

1. Repacholi MH. Health risks from the use of mobile phones. Toxicol Lett 2001; $120(1-3): 323-331$

2. Fanburg VJ, Thannickal BL. Reactive oxygen species in cell signaling. Am J Physiol Lung Cell Mol Physiol2000;279:L1005-L1028.

3. Dalle-Donne I, Rossi R, Giustarini D, Milzani A, Colombo R. Protein carbonyl groups as biomarkers of oxidative stress. Clin Chim Acta 2003;329 (1-2):23-38.

4. Valko M, Leibfritz D, Moncol J, Cronin MTD, Mazur M, Telser J. Free radicals and antioxidants in normal physiological functions and human disease. Int J Biochem Cell Biol 2007;39 (1):44-84.

5. Thomas C, Mackey MM, Diaz AA, Cox DP. Hydroxyl radical is produced via the Fenton reaction in submitochondrial particles under oxidative stress: implications for diseases associated with iron accumulation. Redox Rep2009;14 (3):102-108.

6. Ardan T, Kovaceva J, Cejková J. Comparative histochemical and immunohistochemical study on xanthine oxidoreductase/xanthine oxidase in mammalian corneal epithelium. Acta Histochem 2004;106 (1):69-75.

7. Nishino T, Okamoto K, Kawaguchi Y, Hori H, Matsumura T, Eger BT et al. Mechanism of the conversion of xanthine dehydrogenase to xanthine oxidase: identification of the two cysteine disulfide bonds and crystal structure of a non-convertible rat liver xanthine dehydrogenase mutant. J Biol Chem2005;280 (26):24888-24894.

8. Samejima K, Earnshaw WC. Trashing the genome: the role of nucleases during apoptosis. Nat Rev Mol Cell Biol2005;6 (9):677-688.

9. Oliveri M, Daga A, Cantoni C, Lunardi C, Millo R, Puccetti A. DNase I mediates internucleosomal DNA degradation in human cells undergoing druginduced apoptosis. Eur J Immunol2001;31 (3):743-751.

10. Reiter RJ, Tan DX, Osuna C, Gitto E. Actions of melatonin in the reduction of oxidative stress. A review. J Biomed Sci 2000;7 (6):444-458.
11. Drago F, Frisina M, Grech M, Nicolosi A, Micale V, Nicosia A et al. Dual effects of melatonin on barbiturate-induced narcosis in rats. Neurosci Lett2001;300 (3):176-178

12. Ohkawa H, Ohishi N, Yagi K. Assay for lipid peroxides in animal tissues by thiobarbituric acid reaction. Anal Biochem1979;95 (2):351-358.

13. LevineRL, WilliamsJA,Stadtman ER,ShacterE. Carbonyl assays for determination of oxidatively modified proteins. Methods Enzymol1994;233:346-357.

14. Góth L. A simple method for determination of serum catalase activity and revision of reference range. Clin Chim Acta1991;196 (2-3):143-151.

15. Hashimoto S. A new spectrophotometric assay method of xanthine oxidase in crude tissue homogenate. Anal Biochem 1974;62 (2):426-435.

16. Bartholeyns J, Peeters-Joris C, Reychler H, Baudhuin P. Hepatic nucleases. 1. Methods for the specific determination and characterization in rat liver. Eur J Biochem1975;57 (1):205-211.

17. Lowry OH, Rosebrough NJ, Farr AL, Randall RJ. Protein measurement with the Folin phenol reagent. J Biol Chem 1951;193 (1):265-275.

18. Balci M, Devrim E, Durak I. Effects of mobile phones on oxidant/antioxidant balance in cornea and lens of rats. Curr Eye Res2007;32 (1):21-25.

19. Oktem F, Ozguner F, Mollaoglu H, Koyu A, Uz E. Oxidative damage in the kidney induced by $900-\mathrm{MHz}-\mathrm{emitted}$ mobile phone: protection by melatonin. Arch Med Res 2005;36 (4):350-355.

20. Ozguner F, Bardak Y, Comlekci S. Protective effects of melatonin and caffeic acid phenethyl ester against retinal oxidative stress in long-term use of mobile phone: a comparative study. Mol Cell Biochem 2006;282 (1-2):83-88.

21. Meral I, Mert H, Mert N, Deger Y, Yoruk I, Yetkin A et al. Effects of 900-MHz electromagnetic field emitted from cellular phone on brain oxidative stress and some vitamin levels of guinea pigs. Brain Res2007;1169:120-124.

22. Koyu a, Ozguner F, Yilmaz H, Uz E, Cesur G, Ozcelik N. The protective effect of caffeic acid phenethyl ester (CAPE) on oxidative stress in rat liver exposed to the $900 \mathrm{MHz}$ electromagnetic field. Toxicol Ind Health 2009;25 (6):429-434.

23. Ozgur E, Güler G, Seyhan N. Mobile phone radiation-induced free radical damage in the liver is inhibited by the antioxidants $\mathrm{N}$-acetyl cysteine and epigallocatechin-gallate. Int J Radiat Biol2010;86 (11):935-945.

24. Sokolovic D, Djindjic B, Nikolic J, Bjelakovic G, Pavlovic D, Kocic G et al. Melatonin reduces oxidative stress induced by chronic exposure of microwave radiation from mobile phones in rat brain. J Radiat Res 2008;49 (6):579-586.

25. Ayata A, Mollaoglu H, Yilmaz HR, Akturk O, Ozguner F, Altuntas I. Oxidative stress-mediated skin damage in an experimental mobile phone model can be prevented by melatonin. J Dermatol2004;31 (11):878-883 .

26. Ozgur E. Mobile phone radiation-induced free radical damage in the liver is inhibited by the antioxidants n-acetyl cysteine and. 2010;86 (11):935-945.

27. Esmekaya MA, Ozer C, Seyhan N. 900 MHz pulse-modulated radiofrequency radiation induces oxidative stress on heart, lung, testis and liver tissues. Gen Physiol Biophys 2011;30 (1):84-89.

28. Chevion M, Berenshtein E, Stadtman ER. Human studies related to protein oxidation: protein carbonyl content as a marker of damage. Free Radic Res2000;33 (Suppl):S99-108.

29. Ozguner F, Aydin G, Mollaoglu H, Gökalp O, Koyu A, Cesur G. Prevention of mobile phone induced skin tissue changes by melatonin in rat: an experimental study. Toxicol Ind Health2004;20 (6):133-139.

30. Cohen JJ. Apoptosis. Immunol Today 1993;14 (3):126-130.

31. Barry MA, Reynolds JE, Eastman A. Etoposide-induced apoptosis in human HL-60 cells is associated with intracellular acidification. Cancer Res 1993;53 (Suppl 10):2349-2357.

32. Higuchi Y. Chromosomal DNA fragmentation in apoptosis and necrosis induced by oxidative stress. Biochem Pharmacol2003;66 (8):1527-1535. 